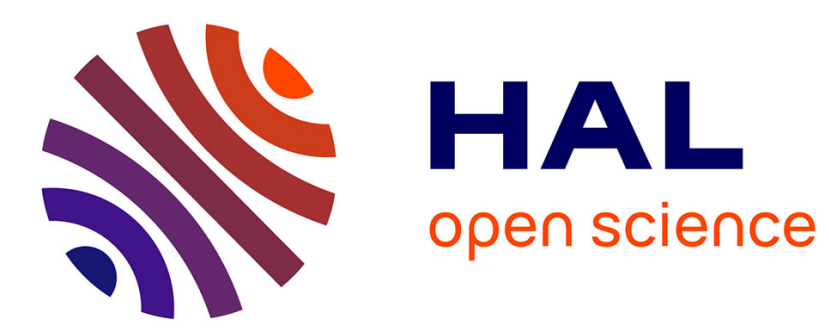

\title{
The Modified Aerosol Pyrolysis as a Preparation Route of Hexaferrite Particles for Magnetic Media
}

\author{
A. Henis, V. Pankov
}

\section{To cite this version:}

A. Henis, V. Pankov. The Modified Aerosol Pyrolysis as a Preparation Route of Hexaferrite Particles for Magnetic Media. Journal de Physique IV Proceedings, 1997, 07 (C1), pp.C1-747-C1-748. 10.1051/jp4:19971305 . jpa-00255072

\section{HAL Id: jpa-00255072 https://hal.science/jpa-00255072}

Submitted on 1 Jan 1997

HAL is a multi-disciplinary open access archive for the deposit and dissemination of scientific research documents, whether they are published or not. The documents may come from teaching and research institutions in France or abroad, or from public or private research centers.
L'archive ouverte pluridisciplinaire HAL, est destinée au dépôt et à la diffusion de documents scientifiques de niveau recherche, publiés ou non, émanant des établissements d'enseignement et de recherche français ou étrangers, des laboratoires publics ou privés. 


\title{
The Modified Aerosol Pyrolysis as a Preparation Route of Hexaferrite Particles for Magnetic Media
}

\author{
A. Henis and V.V. Pankov \\ Institute of Solids Physics and Semiconductors of Academy of Science of Belarus, P. Brovki Str., 17, \\ 220072 Minsk, Belarus
}

\begin{abstract}
Pure and ( $\mathrm{Co}, \mathrm{Ti}$ )-substituted (Ba, Sr)-hexaferrite particles have been prepared by modified coprecipitation and aerosol synthesis technique. The phase composition of the intermediate products and the crystallization process were investigated by DTA-TG, electron microscopy, vibrating sample magnetometry and Mossbauer spectroscopy analyses. The phenomena, connected with transition into superparamagnetic state for the particles of about $10 \mathrm{~nm}$ in size are investigated.
\end{abstract}

\section{INTRODUCTION.}

Hexagonal-ferrite small particles are being widely considered as interesting material for high density magnetic recording media $/ 1 /$. Therefore a great effort is being made to prepare materials with proper size, homogeneous size distribution and controlled magnetic properties. Various techniques have been developed to prepare ultrafine hexaferrites for these purposes. They include the glass crystallization method $/ 2 /$, the wet method $/ 3 /$, the liquid mix-technique $/ 4 /$, colloidal methods $/ 5 /$ and so on. The common feature of these methods is the intimate mixing of ions on the atomic level so that subsequent nucleation and crystallization can occur and induce the phase transition at relatively low temperatures. In addition the particles are free from the stresses present when particle diminution is produced by milling.

In this paper we report modifications in procedures of the aerosol synthesis technique for decreasing the particles size up to $10 \mathrm{~nm}$, based on the addition of the inert components to the starting precursor solutions.

\section{EXPERIMENTAL.}

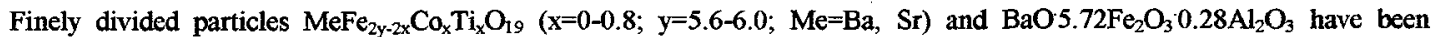
produced by using pyrolisis of an aerosol. The solution was dispersed in an ultrasonic room humidifier with the formation of fine liquid droplets estimated to be less than $1 \mu \mathrm{m}$ in diameter. This aerosol is conveyed by air with a flow rate of $31 / \mathrm{min}$, afterwards it goes through a tube furnace $(\mathrm{D}=5 \mathrm{~cm})$ with different heating sections. The residence time at maximum temperature was about $1 \mathrm{~s}$. Thus the solvent evaporates, leading to the formation of precursor particles in a matrix of inert component.

The $\mathrm{Ba}\left(\mathrm{NO}_{3}\right)_{2}, \mathrm{Fe}\left(\mathrm{NO}_{3}\right)_{3} 9 \mathrm{H}_{2} \mathrm{O}$ (series 1); $\mathrm{BaCO}$, iron citrate, citric acid (series 2); $\mathrm{BaCl}_{2} 2 \mathrm{H}_{2} \mathrm{O}, \mathrm{H}_{3} \mathrm{BO}_{3}$, $\mathrm{Fe}\left(\mathrm{NO}_{3}\right)_{3} \cdot 9 \mathrm{H}_{2} \mathrm{O}, \mathrm{Na}_{2} \mathrm{CO}_{3}$ (series 3); were weighed and mixed with distilled water to form a homogeneous aqueous solution. The hexaferrite particles were synthesized from $0.03 \mathrm{M}$ aqueous solutions. The addition of $30-50$ wt \% of $\mathrm{NaCl}$ was used in the series 1 and 2 . Once the particles were obtained further heat treatment was made at $500-900^{\circ} \mathrm{C}$. After that the powders were washed in distilled water (series 1,2$)$ and in weak acetic acid (series 3 ) to remove the inert components $(\mathrm{NaCl}, \mathrm{BaO}$ $\mathrm{B}_{2} \mathrm{O}_{3}$ ).

During modified coprecipitation technique $\mathrm{FeCl}_{3} 6 \mathrm{H}_{2} \mathrm{O}$ and $\mathrm{Ba}(\mathrm{Sr}) \mathrm{Cl}_{2} 2 \mathrm{H}_{2} \mathrm{O}$ were mixed together and added to the required quantity of $\mathrm{Na}_{2} \mathrm{CO}_{3}$ (series 4). For hexaferrite particles with $\mathrm{Co}$, Ti-substitution $\mathrm{CoCl}_{2} 6 \mathrm{H}_{2} \mathrm{O}$ and $\mathrm{TiCl}_{3}$ were used. Then the $\mathrm{NaCl}$ containing coprecipitates were spray-dried at $250^{\circ} \mathrm{C}$ using a nozzle-type atomizer and heated at $500-900^{\circ} \mathrm{C}$. After $\mathrm{NaCl}$ was dissolved in water finely divided, loose powder was obtained. The samples were characterized by $\mathrm{X}$-ray diffraction, transmission electron microscopy, Mossbauer spectroscopy. Vibrating sample magnetometer was used to measure the magnetic properties.

For Ba-hexaferrite synthesis with composition $\mathrm{BaO} 5,72 \mathrm{Fe}_{2} \mathrm{O}_{3} 0,28 \mathrm{Al}_{2} \mathrm{O}_{3}$ the solution of appropriate $\mathrm{Me}$ citrates was prepared. As the initial reagents the following compounds were chosen: $\mathrm{BaCO}_{3}, \mathrm{Fe}$-citrate and Al-citrate solution (series 5 ). Because Fe-citrate can not be dissolved in water, $2 \mathrm{M}$ citric acid solution was prepared. Fe-citrate is dissolved in this solution 
by heating. After cooling to room temperature $\mathrm{BaCO}_{3}$ and Al-citrate solution are introduced into the prepared solution. The volume of this mixture is increased up to $500 \mathrm{ml}$.

The prepared solution is treated in process of pyrolisis at $800^{\circ} \mathrm{C}$. Hexaferrite obtained after pyrolisis is annealed at 500,550 , $600^{\circ} \mathrm{C}$ during 2 hours.

\section{RESULTS AND DISCUSSION}

The method under consideration produces powder with a hexagonal platelet - like shape and particle size less than $100 \mathrm{~nm}$. An aspect ratio is higher than 10.

$\mathrm{X}$-ray, DTA and Mossbauer spectroscopy analyses lead to the following conclusion. Pure Ba-hexaferrite powder is crystallized at lower temperature $\left(730^{\circ} \mathrm{C}\right)$ than $(\mathrm{Co}, \mathrm{Ti})$ substituted Ba-hexaferrite $\left(820^{\circ} \mathrm{C}\right)$. In contrast, for $(\mathrm{Co}$, Ti) substituted Ba-hexaferrite the formation of intermediate reaction products $\mathrm{BaTiO}_{3}, \mathrm{CoFeO}_{4}$ is revealed. The beginning of interaction in this case takes place at lower temperatures. However, the multistep course of the reaction shifts the synthesis completion to higher temperature range. The room temperature Mossbauer spectra confirm the temperature range of Ba-hexaferrite formation and reveal small amount of the $\mathrm{BaFe}_{2} \mathrm{O}_{4}$ phase as an intermediate phase.

The modified coprecipitation technique has two main features. The first one is that synthesis of hexaferrites is performed in the precess of solid phase diffusion of the cations. This case is realized at the temperatures below $800^{\circ} \mathrm{C}(\mathrm{NaCl}$ melting point). Second, the presence of a liquid $\mathrm{NaCl}$ phase (at the temperatures higher than $800^{\circ} \mathrm{C}$ ) accelerates the reaction due to transfer of reagents by liquid phase diffusion.

To decrease the droplet size up to $1 \mu \mathrm{m}$ and less during spray drying we have started using the method of aerosol pyrolysis. This method gave the opportunity to minimise the amount of segregation during the solidification of the salt solution. In addition, the introduction of the inert component $\left(\mathrm{NaCl}, \mathrm{BaO}-\mathrm{B}_{2} \mathrm{O}_{3}\right)$ to the precursors allows one to prevent aggregation during crystal growth and to synthesize particles with the size close to $10 \mathrm{~nm}$. As it turned out to be, the particles with the least sizes are formed when citrate solutions are used (series 2). For the samples of series 3 extremely high degree of homogeneity in particle size is typical. Among the differences of the samples of series 3 from the other series samples one is that inert component (in this case it is $\mathrm{BaO}-\mathrm{B}_{2} \mathrm{O}_{3}$ ) does not melt at the temperature of pyrolysis and synthesis $\left(900^{\circ} \mathrm{C}\right.$ ) unlike $\mathrm{NaCl}\left(\mathrm{T}_{\text {melt }}-800^{\circ} \mathrm{C}\right)$ and, therefore, the crystallization of hexaferrite particles occurs in solid state conditions. The possibility of some liquid phase formation ( $\mathrm{NaCl}$ matrix melts at temperatures below those of pyrolisis and synthesis) during the synthesis of particles in series 4, 1, obviously, leads to the rapid growth of those hexaferrite particles, which are crystallized in contact with liquid phase. In the present work it was established that coercivity increases with particle size rise in single domain interval. In our case regardless of the precursor for the nonsubstituted particles $\mathbf{H}_{\mathbf{c}}$ sharply begins to decrease below $30 \mathrm{~nm}$ particle size. Such a behaviour indicates on the superparamagnetic nature of such particles randomly oriented uniaxial due to the spins thermal activation.

We observed the decreasing of the saturation magnetization with particle size decreasing. It could be supposed, that the specific magnetization is influenced by the fraction of superparamagnetic particles, by the occupation of the five magnet sublattices and by the thickness of effective nonmagnetic surface layer. On the Mossbauer spectra taken at room temperature the paramagnetic centre line, corresponding to the superparamagnetic fraction begins to appear for the powders in which particles of $20 \mathrm{~nm}$ in diameter and less are present. The areas relationship of the spectrum components indicates that not more than $10 \%$ of substance is in a superparamagnetic state under these conditions.

\section{CONCLUSIONS}

The modified aerosol synthesis technique has been successfully applied to preparation of fine hexaferrite powder with sizes up to $10 \mathrm{~nm}$.

It has been found that pure Ba-hexaferrite powder crystallized at lower temperature $\left(730^{\circ} \mathrm{C}\right)$ than $(\mathrm{Co}, \mathrm{Ti})$ substituted one $\left(820^{\circ} \mathrm{C}\right)$. The temperature ranges and mechanism of crystallization of pure and $(\mathrm{Co}, \mathrm{Ti})$ substituted hexaferrites were established.

Due to high magnetic anisotropy constant of hexaferrites the critical size of particles transition to superparamagnetic state is below $10 \mathrm{~nm}$.

\section{REFERENCES}

1. O. Kubo, T.Ido, H.Yokoyama, IEEE Trans.Magn., MAG-18, (1982), 1122.

2. B.T. Shirk, W.R. Buessm, J. Amer. Ceram. Soc., 53, (1970), 192.

3. K. Haneda, C. Miyakawa, H. Kojima, J. Amer. Ceram. Soc., 57, (1974), 354.

4. M. Vallet-Regi, P. Rodriguez, X. Obradors et al., J. Physique, 46, (1985), C6-335.

5. E. Matijevic, J.Colloid Interface Sci., 117, (1987), 593.

6. O.Kubo, T.Ido, H.Yokoyama et al., J. Appl. Phys., 57, (1985), 4280. 